\title{
Effect of Glue and Temperatures on Mechanical Properties of Starch-Based Biodegradable Composites Reinforced with Bagasse Fibers
}

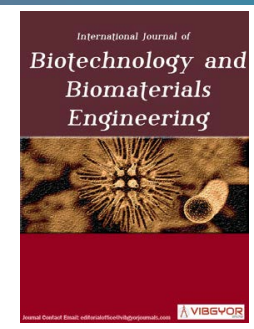

\section{Sherif Mehanny', Lamis Darwish'2, Abd El Haleem, M El Habbak', Emad El-Kashif', Mahmoud Farag ${ }^{3}$ and Hamdy Ibrahim ${ }^{4}$}

${ }^{1}$ Department of Mechanical Design and Production, Faculty of Engineering, Cairo University, Egypt

${ }^{2}$ Department of Biomedical Engineering, Faculty of Engineering, Helwan University, Egypt

${ }^{3}$ Department of Mechanical Engineering, School of Sciences and Engineering, The American University in Cairo, Egypt

${ }^{4}$ Department of Mechanical Engineering, University of Tennessee at Chattanooga, USA

\begin{abstract}
The aim of this work is to investigate the effect of adding animal glue on the mechanical properties of a bagasse fibers-reinforced starch composite prepared at different hot-pressing temperatures $\left(110^{\circ} \mathrm{C}, 140{ }^{\circ} \mathrm{C}\right.$ and $\left.170{ }^{\circ} \mathrm{C}\right)$. Scanning electron microscope (SEM) was used for morphological analysis of composite samples and universal testing machine (UTS) was utilized to measure tensile strength and modulus of elasticity of samples involved. The tensile properties of the prepared composites with glue were higher than those for the glue-free composites. In addition, the processing temperature of $140{ }^{\circ} \mathrm{C}$ resulted in the highest strength and Young's modulus of $21 \mathrm{MPa}$ and $3395 \mathrm{MPa}$, respectively. The addition of glue was found to be very promising to enhance the mechanical properties of bagasse fibers-reinforced starch composites mainly at low hot-pressing temperatures (below $140{ }^{\circ} \mathrm{C}$ ).
\end{abstract}

Keywords

Lignocellulosic fibers, Bagasse fibers, Biodegradable composites, Starch, Glue

\section{Introduction}

During the last two decades, a considerable amount of research has been focused on the development of eco-friendly "green" biodegradable composites that can replace the artificially-synthesized petroleum-based composites [1]. Such efforts are attempting to satisfy the increased demand of creating a resource-circulating society, which poses no resource-shortage-related problems [2]. Biode- gradable polymers such as polyglycolic acid (PGA), poly-L-Lactic acid (PLLA), chitosan, polycaprolactone (PCL) and thermoplastic starch (TPS) are eco-friendly abundant materials that have shown excellent properties for different application (e.g. excellent biocompatibility for biomedical application). However, their lower mechanical properties and poor long-term stability limit their use for such applications [3]. For instance, TPS has very low

*Corresponding author: Hamdy Ibrahim, Ph.D., Department of Mechanical Engineering, University of Tennessee at Chattanooga, Tennessee, 43703, USA

Accepted: March 12, 2019; Published: March 14, 2019

Copyright: (C 2018 Mehanny S, et al. This is an open-access article distributed under the terms of the Creative Commons Attribution License, which permits unrestricted use, distribution, and reproduction in any medium, provided the original author and source are credited.

Mehanny et al. Int J Biotechnol Biomater Eng 2019, 1:002 
mechanical properties (e.g. strength of $3.7 \mathrm{MPa}$ ), fast biodegradation rate and low water resistance which causes a quick deterioration of its properties once being in use [4].

Lignocellulosic fibers, such as banana [5], hemp [6], kenaf [7], or bagasse [8-10] have been used as reinforcements for different types of biodegradable resins in order to enhance the mechanical, chemical and physical properties. This can be attributed to the superior mechanical, thermal and physical properties of lignocellulosic fibers compared to biodegradable resins [11].

Starch is one of the most widely abundant materials that can be plasticized easily and at low cost making it a very attractive material for developing biodegradable composites. Starch is a natural hydrophilic polysaccharide polymer with 20-45\% crystallinity [12]. Adding water to starch, while heating, causes swelling and bursting of starch granules leading to a loss of its crystallinity. This phenomenon is known as the gelatinization process [13]. Also, adding glycerin as a plasticizer is an important plasticization step to improve the mechanical and the physical properties towards producing TPS $[12,14]$.

Adhesion between fibers and matrix is known to have a significant impact on the properties of biodegradable composites especially the mechanical properties. Several techniques have been introduced to enhance the adhesion between the fibers and matrix, such as fibers chemical treatment [15], plasma treatments [16] and the use of nanofibers [17].

Animal glue is a natural adhesive material that has been used for various applications. It is usually extracted from animal connective tissues such as bone and skin. Mentioned tissues are subjected to consecutive physical and chemical processes to extract collagen fibers which break down under the effect of heat to form an amorphous structure of gelatin, the final animal glue product [18]. Animal glue is generally advantageous compared to synthetic adhesives. Deploying animal glue applications is a feasible way to recycle more than 10 million tons of skin and hide wastes. Moreover, animal glue is easy to apply, fast to tack and set, in addition it manifests high strength [18].

In this article, we added animal glue to a bagasse/starch-based composite as an adhesive agent between bagasse fibers and TPS matrix. This is the first work investigating the effect of adding animal glue on the microstructural and mechanical properties of a completely biodegradable composite. In addition, the effect of the composite's preparation temperature (hot pressing temperature) was investigated.

\section{Materials and Methods}

\section{Materials}

Native corn starch with a moisture content of $2 \%$ on mass basis was used. This moisture content was considered in further preparations for the starch blends. Bagasse stalks was supplied by a local sugarcane mills as the source of the bagasse fibers and sodium hydroxide $(\mathrm{NaOH})$ produced by Fluka AG, Switzerland was used to prepare the bagasse fibers. Glycerin of $99.7 \%$ purity and stearic acid with $98 \%$ assay ratio were used in the preparation of the composites. Animal glue gel with 50 wt.\% concentration was obtained from Lion Glue Co.

\section{Preparation}

Bagasse fibers: Bagasse fibers were prepared as explained in the previously published work [10]. Briefly, bagasse stalks were soaked in water for two days (retting). Retting is essential to allow bacterial colonies breeding so they can feed on lignin and hemicellulose facilitating the process of fibers extraction. After retting, bagasse rinds were separated from the pith then they were cut into small pieces with a length of $20-30 \mathrm{~mm}$. The rind small pieces were stricken in blender for 5 minutes to extract the needed bagasse fibers. The fibers were then dried for 3 hours at $120^{\circ} \mathrm{C}$, then sifted to remove lignin powder. Fibers were then soaked in a $1 \% \mathrm{NaOH}$ solution for 2 hours. Finally, the fibers were washed in distilled water and oven dried at $120^{\circ} \mathrm{C}$ for 1 hour.

TPS/glue matrix: Native corn starch was mixed with glycerin (30 wt.\% of dry starch) for 10 minutes at $60{ }^{\circ} \mathrm{C}$, water (20 wt.\% of dry starch) was then added to the mix. The mixing process continued for another 5 minutes at $60^{\circ} \mathrm{C}$ until TPS was obtained. A TPS emulsion was prepared by mixing the TPS with water (TPS:Water weight ratio of 1:3) to facilitate the addition of glue and the penetration of the matrix through the bagasse fibers during the preparation of the composites. 20 wt.\% animal glue gel was added to the TPS emulsion. This results 
in a 10 wt.\% glue content of the final prepared composites.

Composite preparation: Steel die of cavity with the dimensions of $120 \times 80 \times 2 \mathrm{~mm}$ was used to prepare the composite samples. The die surfaces were covered with stearic acid to act as a mold releasing agent. Bagasse fibers were distributed regularly in the die cavity (fiber content of $40 \mathrm{wt} . \%$ ) and the emulsified matrix was then poured on the fibers. The die was placed on a Carver Laboratory press(ModelC), then it was subjected to a preheating stage 30 minutes to remove excess water from the emulsion. The samples were then hot-pressed under $5 \mathrm{MPa}$ at 3 different temperatures $\left(110{ }^{\circ} \mathrm{C}\right.$, $140{ }^{\circ} \mathrm{C}$ and $170^{\circ} \mathrm{C}$ ) for 30 minutes. The preheating and hot-pressing durations were established from previous studies as the optimum durations needed for TPS polymerization [4]. Finally, the die was air cooled to $45^{\circ} \mathrm{C}$ for 40 minutes using a fan. Table 1 lists the chemical compositions of the two types of the prepared composite samples. Figure 1 shows a flow diagram of the experimental procedure followed to prepare the composite samples in this study.

\section{Microscopic characterization}

The fracture surface of the prepared starch/ glue matrix and composites after the tensile test was investigated using SEM. The SEM investigation was conducted using a ZEISS-SEM under 1e-4 mbar and $8 \mathrm{kV}$. Samples were investigated without any special coating. The morphology of the used commercial native corn starch was also characterized using SEM.

\section{Mechanical characterization}

Mechanical properties of the prepared composites were studied by conducting tensile testing using an Instron-universal testing machine, model 3382. Samples of dimensions $80 \times 8 \times 2 \mathrm{~mm}$ were tested following the ASTM-D3039/D3039M-08

Table 1: The weight content of chemical constituents for the two prepared composite samples.

\begin{tabular}{|l|l|l|l|}
\hline Composite type & Bagasse fibers (wt.\%) & Starch (TPS) (wt.\%) & Glue (wt.\%) \\
\hline Glue-free composite & 40 & 60 & 0 \\
\hline Starch/glue composite & 40 & 50 & 10 \\
\hline
\end{tabular}

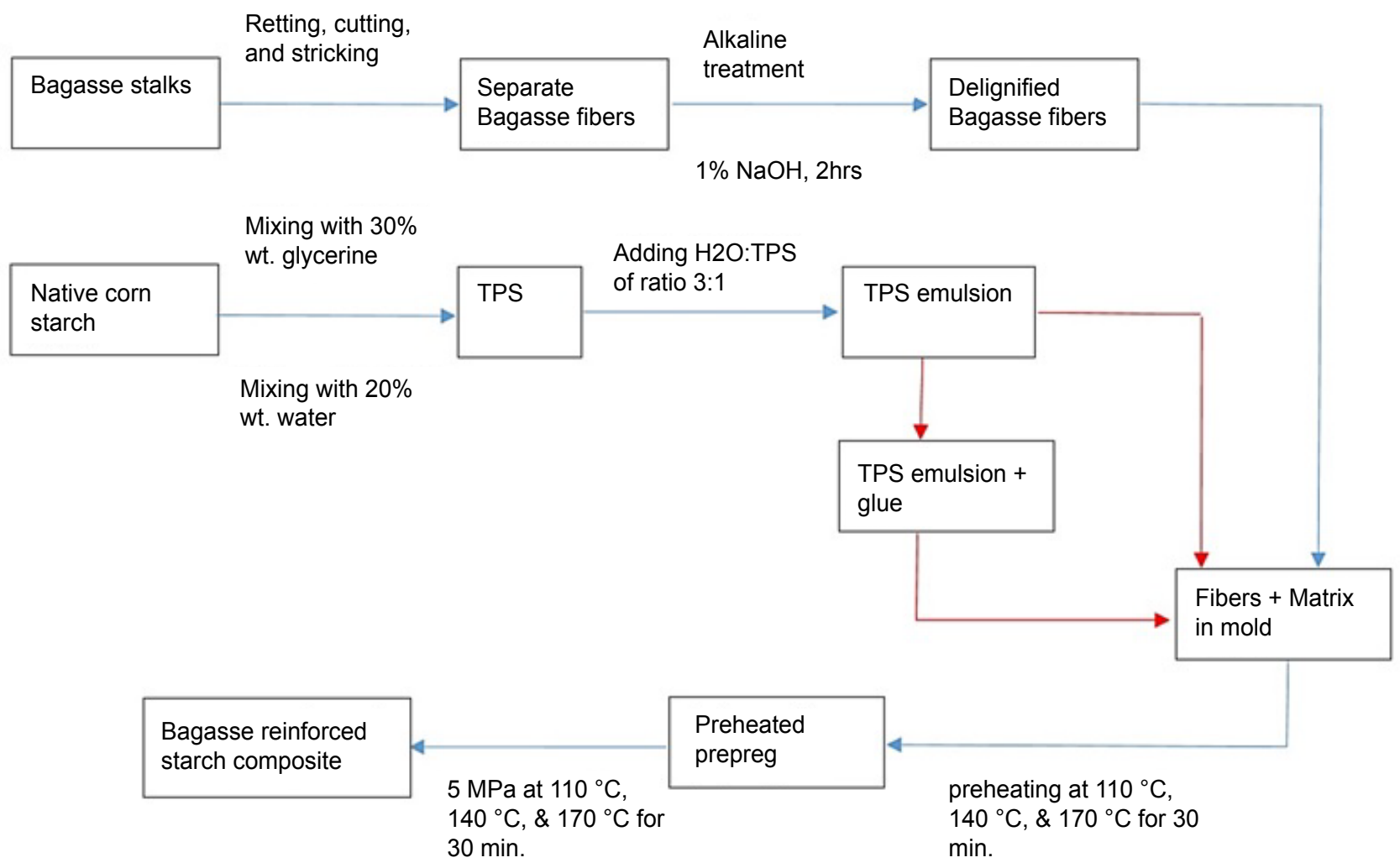

Figure 1: Flow diagram of the samples' preparation procedure. 
standard at a crosshead speed of $2 \mathrm{~mm} / \mathrm{min}$ [19]. An average of 5 samples was considered for each type of the tested composites.

\section{Physical analysis}

The density of the prepared matrix, treated fibers, and composites were measured experimentally. Then the theoretical values of the composite densities and the resulting void fraction were calculated according to the following equations:

$$
\begin{aligned}
& V_{f}=\frac{\rho_{m} W_{f}}{\rho_{m} W_{f}+\rho_{f} W_{m}} \\
& \rho_{c}=\rho_{f} V_{f}+\rho_{m} V_{m}
\end{aligned}
$$$$
\text { Void fraction } \%=\left(\frac{\rho_{c}-\rho_{\text {exp }}}{\rho_{c}}\right) \times 100
$$

Where $\rho_{c}$ is the final calculated density of composite, $\rho_{f}$ is the treated fibers density, $V_{f}$ is the fiber volume fraction, $W_{f}$ is the fiber weight fraction, $\rho_{m}$ is the matrix density, $V_{m}$ is the matrix volume fraction, $W_{m}$ is the matrix weight fraction, and $\rho_{\text {exp }}$ is the experimentally measured density of the composite.

\section{Results and Discussion}

Figure $2 \mathrm{a}$ and Figure $1 \mathrm{~b}$ show the morphological analysis of the commercially-available native corn starch that was used to prepare the thermoplastic starch matrix. Native corn starch showed irregular and stone-like shape particles. This morphology is in agreement with the results found in the literature [20].

Figure $3 a$ and Figure $2 b$ show the fracture surface of the of starch/glue matrix hot-pressed at $140{ }^{\circ} \mathrm{C}$ by emulsion technique. Homogenous

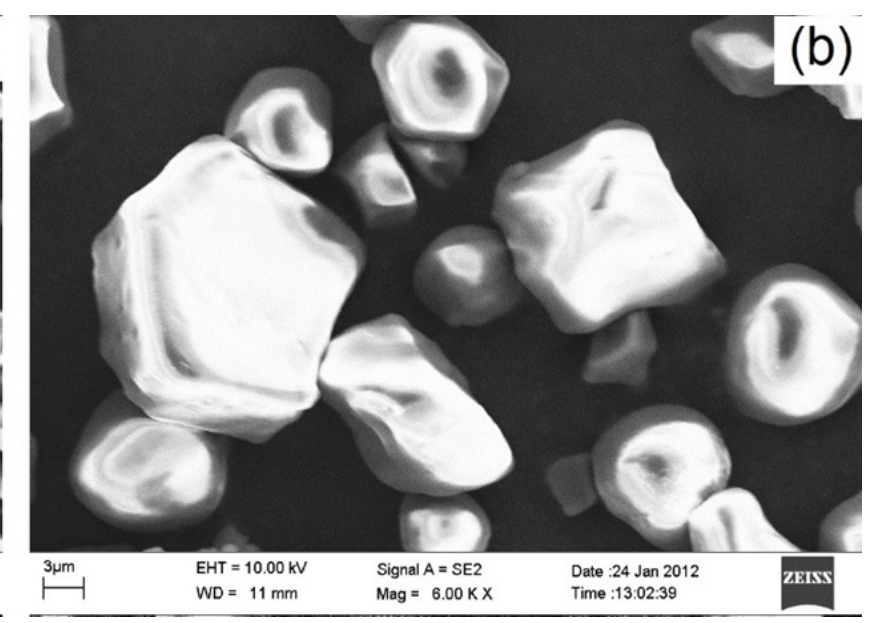

Figure 2: SEM micrographs of native corn starch particles, (a) and (b), irregular and stone-like particles.

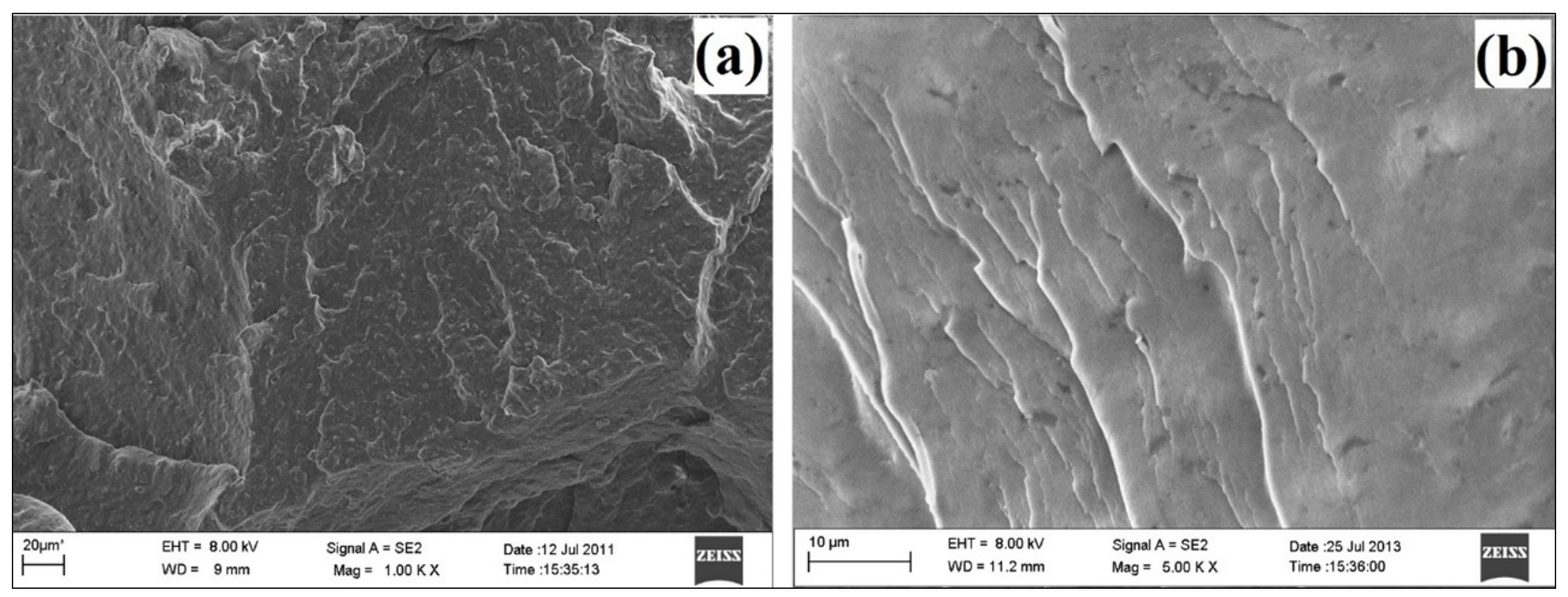

Figure 3: SEM investigation of the starch/glue matrix fracture surface prepared by emulsification and hotpressing at $140{ }^{\circ} \mathrm{C},(\mathrm{a})$ and (b). 

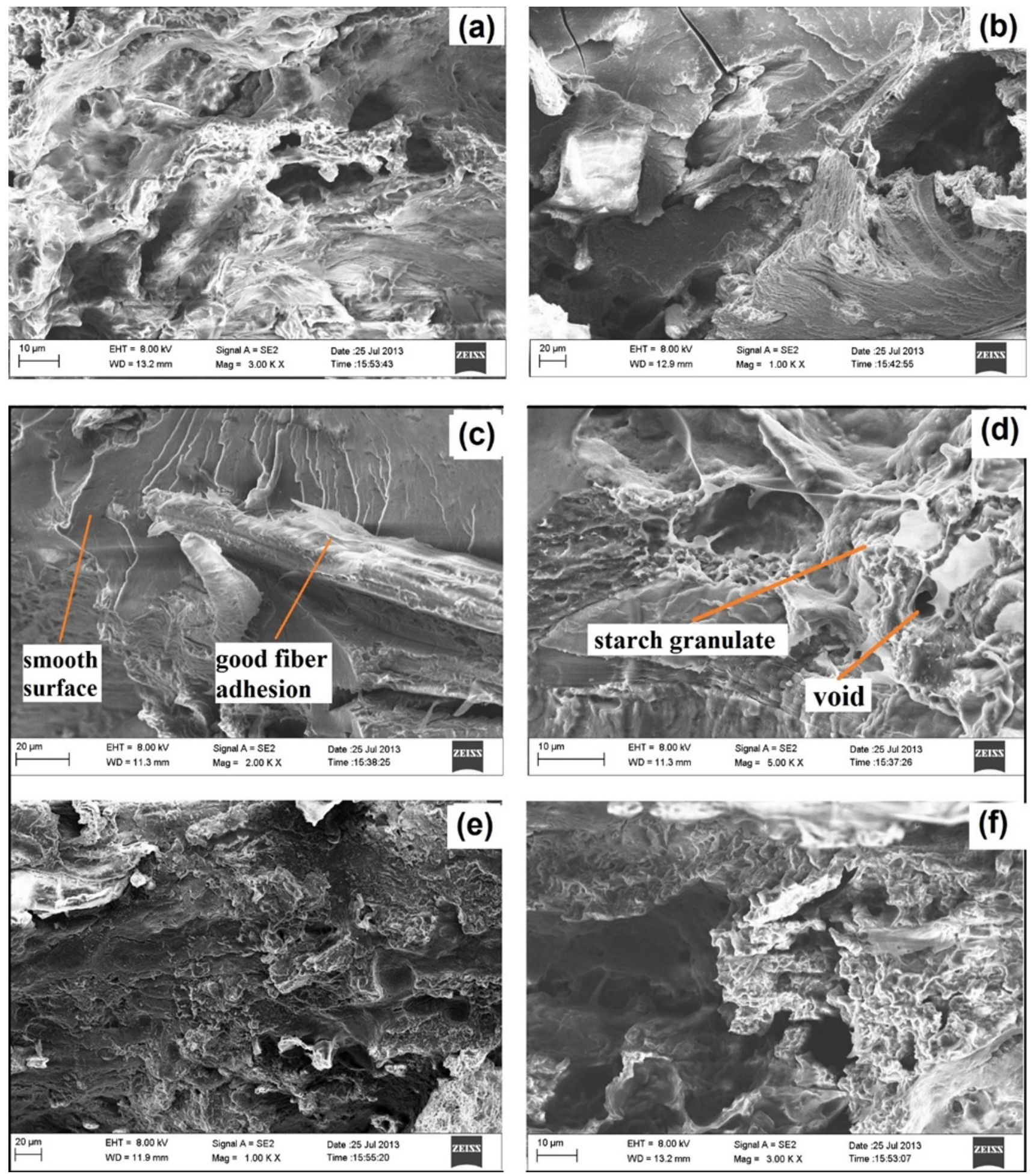

Figure 4: The fracture surface of starch/glue-based bagasse composite; (a) and (b) hot-pressed at $110{ }^{\circ} \mathrm{C} ;(\mathrm{c})$ and (d) hot-pressed at $140{ }^{\circ} \mathrm{C}$; (e) and (f) hot-pressed at $170^{\circ} \mathrm{C}$.

appearance confirms that starch and glue were successfully blended during the emulsification and hot-pressing processes. Also, the smooth fracture surface with cleavage-like regions implies insufficient ductility as observed in other studies for emulsified starch matrix [4].
The fracture surface after the tensile test for the starch/glue composites under $110^{\circ} \mathrm{C}, 140{ }^{\circ} \mathrm{C}$ and $170{ }^{\circ} \mathrm{C}$ are shown in Figure 4 . Smooth fracture surface, fiber wettability, and good adhesion between matrix and fiber (good matrix/fiber interface) for the composites prepared at $110{ }^{\circ} \mathrm{C}$ and $140{ }^{\circ} \mathrm{C}$ can be easily observed in Figure $4 a$, 
Figure $4 b$, Figure $4 c$ and Figure $4 d$. This confirms that hot pressing the starch/glue composites at 140 ${ }^{\circ} \mathrm{C}$ was sufficient to crystallize starch and glue as a matrix for the desired bagasse fibers reinforced composite. Figure $4 d$ shows that even with the success in the plasticization and crystallization of the starch/glue matrix at $140{ }^{\circ} \mathrm{C}$, few voids and starch granulates (whiter color) seem to be not well-gelatinized. However, the presence of such areas was very scarce in the prepared composites which did not have a noticeable influence on the composites' mechanical properties. For the fracture surface of the composites prepared at $170{ }^{\circ} \mathrm{C}$, it can be seen that these composites exhibit random structure with a non-uniform surface. This can be attributed to the thermal degradation of glue that was promoted at the high pressing temperature $\left(170{ }^{\circ} \mathrm{C}\right)$ which may lead to a deterioration in the final composite's mechanical properties.

Tensile strength results are depicted in Figure 5. It can be seen that at $110^{\circ} \mathrm{C}$, as the lowest hotpressing temperature, the addition of glue to the starch-based composite resulted in the highest increase in the tensile strength, more than 5 times from $4 \mathrm{MPa}$ to $20.7 \mathrm{MPa}$. Whereas, there was no significant difference in the composites' tensile strength of the glue-free and the starch/ glue samples at higher preparation temperatures (above $140{ }^{\circ} \mathrm{C}$ ). This implies that glue can provide starch-based composites with a significantly higher strength at lower preparation temperatures.

This behavior agrees with the findings of Kozlov, et al. [21] who found that the highest strength for films made of pure gelatin (glue) was $11 \mathrm{MPa}$ at processing temperature of $100{ }^{\circ} \mathrm{C}$, while films prepared at $150^{\circ} \mathrm{C}$ and $220^{\circ} \mathrm{C}$ showed lower tensile strength of $8.5 \mathrm{MPa}$ and $4.5 \mathrm{MPa}$, respectively. This confirms that for composites that may incorporate glue, strength is inversely related to the processing temperature. This justifies why the starch/glue bagasse composite samples did not show significant increase in the tensile strength at the higher processing temperatures. Also, thermal gravimetry results in the literature show that pure gelatin loses $10 \%$ of its mass at $155{ }^{\circ} \mathrm{C}[21,22]$, which leads to weak peptides and amino acids, compared to $191.2^{\circ} \mathrm{C}$ for glue-free starch matrix in order to show the same degradation behavior [23]. The fact that the degradation temperature of glue is lower than starch, leads to anticipate gelatin samples

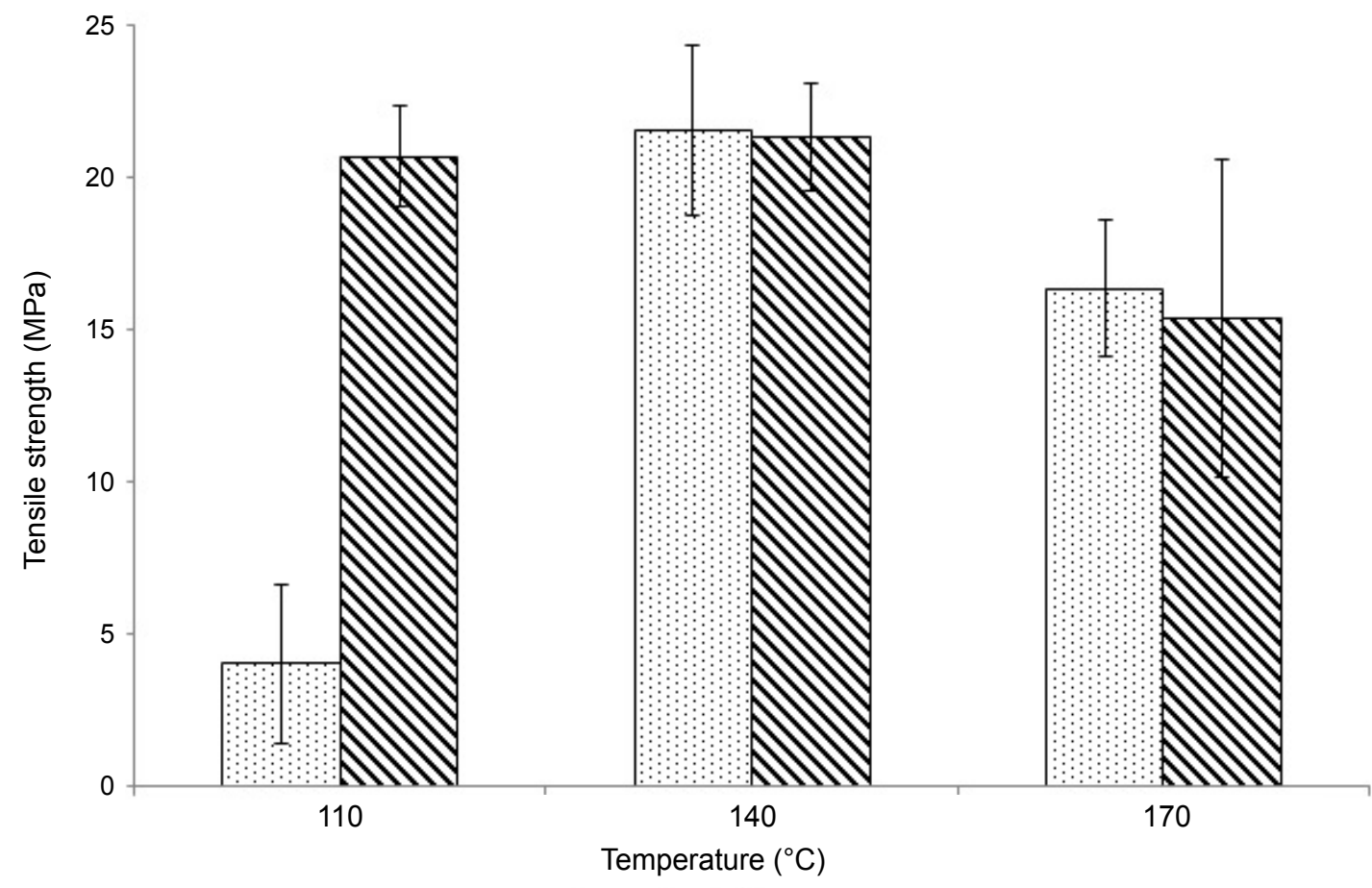

Figure 5: The effect of processing temperature and the addition of glue on the tensile strength of starch-based bagasse composites. 


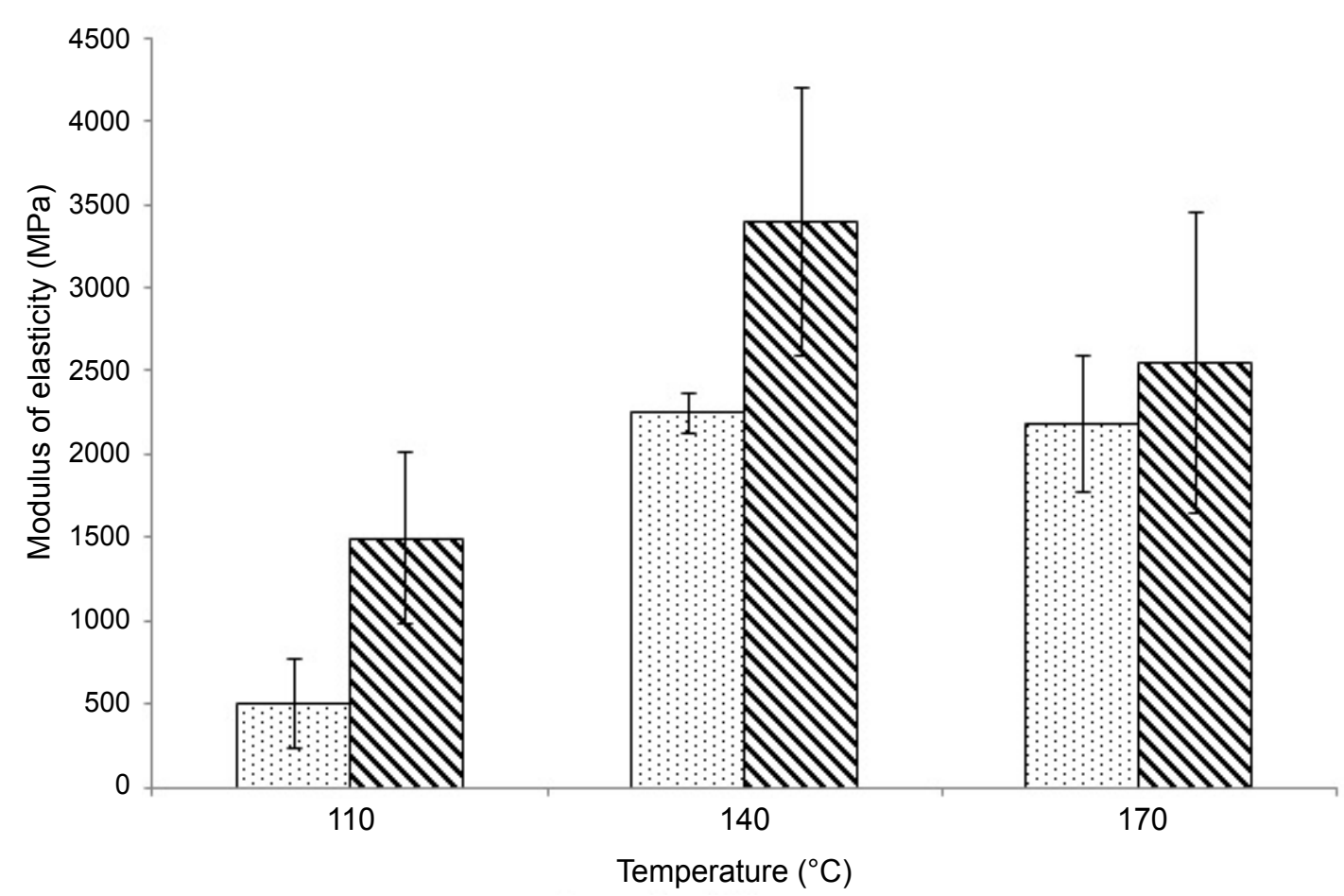

Figure 6: The effect of processing temperature and the addition of glue on the tensile modulus of elasticity of starch-based bagasse composites.

crystallization in lower temperature compared to starch, that conforms to the significantly higher strength of glue at lower processing temperatures.

Figure 6 shows the elastic modulus of gluefree and starch/glue composite samples prepared at different temperatures. Generally, the starch/ glue composites recorded higher elastic modulus values in comparison to the glue-free starch-based composites. For example, the addition of glue to the starch-based bagasse composites increased the elastic modulus from $500 \mathrm{MPa}$ to $1496.6 \mathrm{MPa}$, and from $2246 \mathrm{MPa}$ to $3395 \mathrm{MPa}$ for samples processed at $110{ }^{\circ} \mathrm{C}$ and $140{ }^{\circ} \mathrm{C}$, respectively. Composite samples prepared at $140{ }^{\circ} \mathrm{C}$ had the highest elastic modulus for both glue-free and starch/glue bagasse composites. Whereas, the addition of glue to the starch-based bagasse composites prepared at $170{ }^{\circ} \mathrm{C}$ did not result in a significant increase in the elastic modulus.

The fact that starch/glue composite samples showed comparably high modulus of elasticity than glue-free composites can be attributed to the fact that gelatin behaves as a brittle material regardless molecular conformation [21]. Also, the fractal dimension (a measure for the complexity of the $2 \mathrm{D}$ chains composition) of the plastic, and the ratio between elastic storage modulus $\left(G^{\prime}\right)$ and viscous loss modulus ( $\left.G^{\prime \prime}\right)$ both increase by increasing the glue content $[24,25]$. This leads to increasing entanglements complexity between polymer chains, hence raising the starch/glue composite's modulus of elasticity.

A summary of the tensile properties of the starch/glue composites prepared at the three different hot-pressing temperatures can be found in Table 2. It can be seen that similar to the significant increase in the yield and ultimate tensile strength of the composites at $100{ }^{\circ} \mathrm{C}$, the ductility was increased significantly after the addition of glue. For instance, the max strain for composites hot-pressed at $110^{\circ} \mathrm{C}$ increased from $1.88 \%$ for the glue-free composite to $3.69 \%$ after the addition of glue. Also, Table 3 is an attempt to compare the mechanical strength obtained in this study with some of the other promising biocomposites in the literature.

The density of treated bagasse fibers and starch/ glue matrix were measured and found to be 1.36 
Table 2: The tensile properties of the two prepared composite samples at different temperatures.

\begin{tabular}{|l|l|l|l|l|}
\hline $\begin{array}{l}\text { Composite preparation } \\
\text { conditions }\end{array}$ & $\begin{array}{l}\text { Modulus of Elasticity } \\
(\mathbf{G P a})\end{array}$ & $\begin{array}{l}\text { Yield strength } \\
(\mathrm{MPa})\end{array}$ & $\begin{array}{l}\text { Ultimate tensile } \\
\text { strength }(\mathrm{MPa})\end{array}$ & Max strain (\%) \\
\hline Glue-free $\left(110^{\circ} \mathrm{C}\right)$ & 0.5 & 2.6 & 4.03 & 1.88 \\
\hline Starch/glue $\left(110^{\circ} \mathrm{C}\right)$ & 1.5 & 6.04 & 20.68 & 3.69 \\
\hline Glue-free $\left(140^{\circ} \mathrm{C}\right)$ & 2.25 & 5.91 & 21.52 & 3.84 \\
\hline Starch/glue $\left(140^{\circ} \mathrm{C}\right)$ & 3.4 & 6.96 & 21.31 & 2.34 \\
\hline Glue-free $\left(170^{\circ} \mathrm{C}\right)$ & 2.18 & 4.66 & 16.34 & 1.95 \\
\hline Starch/glue $\left(170^{\circ} \mathrm{C}\right)$ & 2.55 & 4.26 & 15.38 & 3.24 \\
\hline
\end{tabular}

Table 3: Preparation methods and resulting tensile strength of various biocomposites in the literature in comparison to those in this study.

\begin{tabular}{|c|c|c|c|c|}
\hline Fiber type and percentage & Matrix type & Preparation method & Tensile strength (MPa) & Ref. \\
\hline $\begin{array}{l}\text { Kenaf ( } 50 \% \text { wt.) } \\
\text { Unidirectional fibers }\end{array}$ & PLA & $\begin{array}{l}\text { Pressing at } 10 \mathrm{MPa} \text { and } 160^{\circ} \mathrm{C} \\
\text { for } 5 \mathrm{~min}\end{array}$ & 297 & [7] \\
\hline $\begin{array}{l}\text { Flax (30\% wt.) } \\
\text { Cordenka (30\% wt.) }\end{array}$ & PLA & $\begin{array}{l}\text { Pressing at } 18 \mathrm{MPa} \text { and } 170^{\circ} \mathrm{C} \\
\text { for } 5 \mathrm{~min}\end{array}$ & $\begin{array}{l}54 \text { (Flax) } \\
58 \text { (Cordenka) }\end{array}$ & {$[26]$} \\
\hline $\begin{array}{l}\text { Abaca (30\% wt.) } \\
\text { Cordenka (30\% wt.) }\end{array}$ & PLA & $\begin{array}{l}\text { Injection at } 500 \text { bar and } 200 \\
\mathrm{~mm} / \mathrm{s}\end{array}$ & $\begin{array}{l}74 \text { (Abaca) } \\
92 \text { (Cordenka) }\end{array}$ & {$[27]$} \\
\hline Flax (30\% wt.) & PLA & Pressing at $70 \mathrm{MPa}$ and $50^{\circ} \mathrm{C}$ & 52 & [11] \\
\hline Bamboo (50\% wt.) & Starch & $\begin{array}{l}\text { Pressing at } 20 \mathrm{MPa} \text { and } 130^{\circ} \mathrm{C} \\
\text { for } 5 \mathrm{~min}\end{array}$ & 42 & {$[28]$} \\
\hline $\begin{array}{l}\text { Newspaper fine fibers } \\
\text { (30\% wt.) }\end{array}$ & Starch & Pressing at $150{ }^{\circ} \mathrm{C}$ for $10 \mathrm{~min}$ & 30 & [29] \\
\hline Bagasse (10\% wt.) & Starch & Extrusion at $100^{\circ} \mathrm{C}$ and $40 \mathrm{rpm}$ & 1.7 & [30] \\
\hline Bagasse (40\% wt.) & Starch/glue & $\begin{array}{l}\text { Pressing at } 5 \mathrm{MPa} \text { and } 140^{\circ} \mathrm{C} \\
\text { for } 30 \mathrm{~min}\end{array}$ & 21 & This study \\
\hline
\end{tabular}

$\mathrm{g} / \mathrm{cm}^{3}$ and $1.3975 \mathrm{~g} / \mathrm{cm}^{3}$, respectively. The experimental measurements and the calculated values of the 40 wt.\% bagasse composites prepared at 140 ${ }^{\circ} \mathrm{C}$ are shown in Figure 7. Both types of the prepared bagasse composites (glue-free and starch/ glue) have densities close to the calculated values, which means a very low void fraction (porosity) for both types of the prepared bagasse composites. The void fraction values were $0.07 \%$ for the gluefree composite, and $0.14 \%$ for the starch/glue composite. This can be attributed to the good penetration of the matrix through bagasse fibers during the hot-pressing process due to the use of the emulsified matrix.

\section{Conclusions}

Bagasse fiber-reinforced starch composite with the addition of animal glue was successfully prepared by using emulsification and hot-pressing (compression molding). The SEM investigation of the prepared composites fracture surface revealed good matrix/fiber interface and fiber wettability which confirms strong adhesion between the starch/glue matrix and bagasse fibers. Also, smooth and homogenous matrix fracture surface confirms the crystallization of both starch and glue during the hot-pressing process. Starch/glue bagasse composite samples prepared at $140{ }^{\circ} \mathrm{C}$ processing temperature showed the highest mechanical properties compared to those prepared at $110{ }^{\circ} \mathrm{C}$ and $170{ }^{\circ} \mathrm{C}$. At the lowest processing temperature of $110^{\circ} \mathrm{C}$, the addition of glue to the starch-based bagasse composite resulted in a significant increase in tensile strength. However, as the processing temperature increases, there was no enhancement in the tensile strength. This can be attributed to the lower thermal degradation temperature of glue compared to starch. Meanwhile, the addition of 


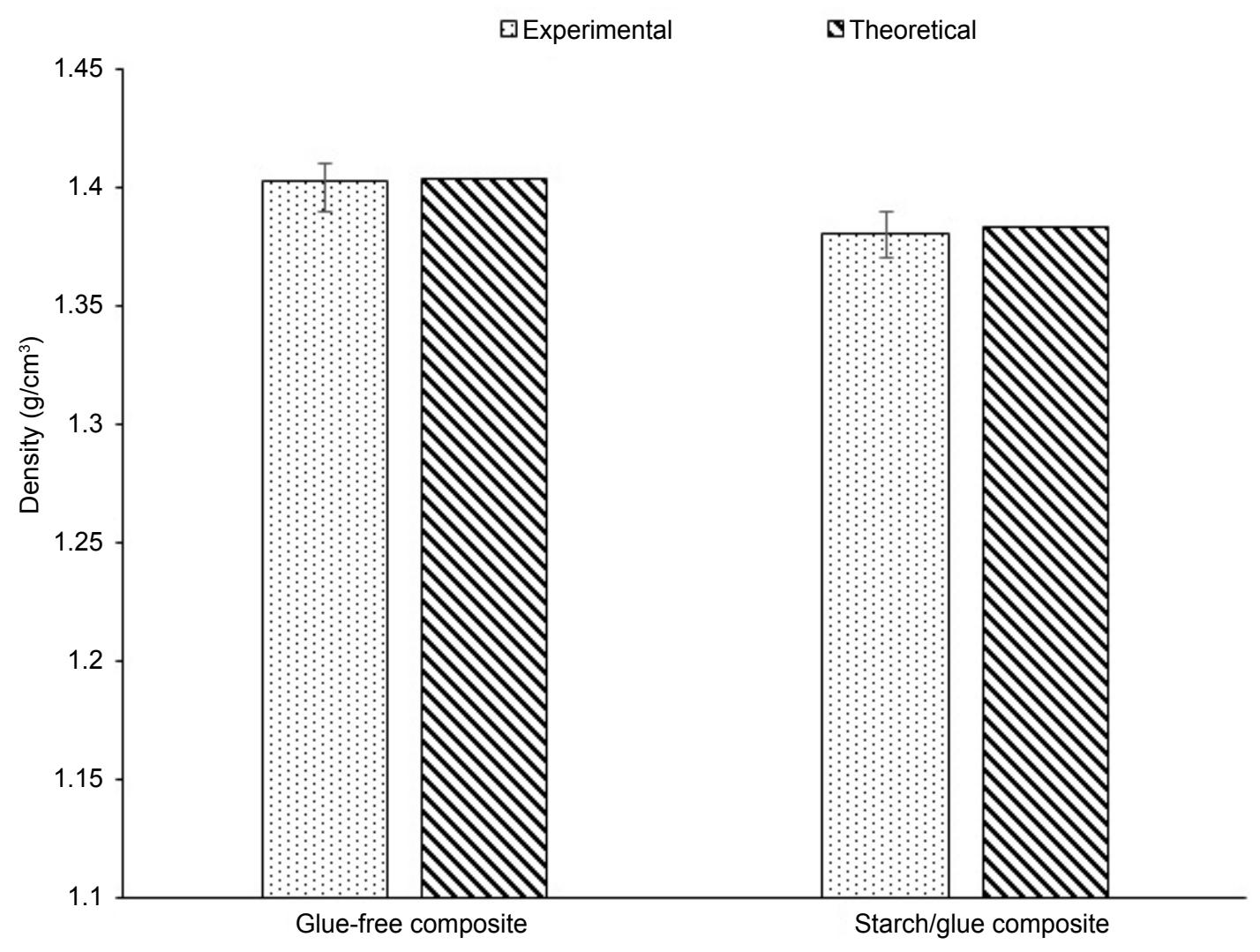

Figure 7: Measured and calculated densities for glue-free bagasse composite, and starch/glue bagasse composite prepared at $140^{\circ} \mathrm{C}$.

glue to the bagasse starch-based composites resulted in a significant increase in the elastic modulus at all processing temperatures. This can be interpreted by the conformation complexity of the gelatin chains and their entanglements. The addition of animal glue showed very promising results in producing strong and reliable lignocellulosic starch-based composites at lower processing temperatures which may significantly reduce the total fabrication cost of such biodegradable composites. Future investigations of adding different glue contents to starch-based composites with various fiber types and contents should be conducted to optimize mechanical and biodegradation performance of these biodegradable materials.

\section{References}

1. Facca AG, MT Kortschot, N Yan (2006) Predicting the elastic modulus of natural fibre reinforced thermoplastics. Composites Part A: Applied Science and Manufacturing 37: 1660-1671.

2. Li CG (2011) Thermal and mechanical properties of bagasse microcrystalline cellulose reinforced PLA composites. Advanced Materials Research, Trans
Tech Publ.

3. Ibrahim H, Esfahani SN, Poorganji B, Dean D, Elahinia M (2017) Resorbable bone fixation alloys, forming, and post-fabrication treatments. Mater Sci Eng C Mater Biol Appl 70: 870-888.

4. Ibrahim H, Farag M, Megahed H, Mehanny S (2014) Characteristics of starch-based biodegradable composites reinforced with date palm and flax fibers. Carbohydr Polym 101: 11-19.

5. Ramesh M, T Sri Ananda Atreyaa, US Aswin, H Eashwar, C Deepa (2014) Processing and mechanical property evaluation of banana fiber reinforced polymer composites. Procedia Engineering 97: 563572.

6. Takagi H (2005) Biodegradation behavior of starchbased "green" composites reinforced by Manila hemp fibers. Proceedings of 3rd International Conference on Eco-Composites.

7. Ochi S (2008) Mechanical properties of kenaf fibers and kenaf/PLA composites. Mechanics of Materials 40: 446-452.

8. Cao Y, S Shibata, I Fukumoto (2006) Mechanical properties of biodegradable composites reinforced 
with bagasse fibre before and after alkali treatments. Composites Part A: Applied science and Manufacturing 37: 423-429.

9. Shibata S, Y Cao, I Fukumoto (2005) Effect of bagasse fiber on the flexural properties of biodegradable composites. Polymer Composites 26: 689-694.

10. Mehanny S (2012) Fabrication and characterization of starch based bagasse fiber composite. ASME 2012 International Mechanical Engineering Congress and Exposition, American Society of Mechanical Engineers.

11.Oksman K, M Skrifvars, JF Selin (2003) Natural fibres as reinforcement in polylactic acid (PLA) composites. Composites Science and Technology 63: 1317-1324.

12.Satyanarayana KG, GGC Arizaga, F Wypych (2009) Biodegradable composites based on lignocellulosic fibers-An overview. Progress in Polymer Science 34: 982-1021.

13. Belitz H, W Grosch, P Schieberle (2004) Food chemistry. 3rd revised English edition. Springer, Berlin.

14. Hamdy Ibrahim, Sherif Mehanny, Lamis Darwish, Mahmoud Farag (2018) A comparative study on the mechanical and biodegradation characteristics of starch-based composites reinforced with different lignocellulosic fibers. Journal of Polymers and the Environment 26: 2434-2447.

15.Alawar A, AM Hamed, K Al-Kaabi (2009) Characterization of treated date palm tree fiber as composite reinforcement. Composites Part B: Engineering 40: 601-606.

16. De Farias JG, Cavalcante RC, Canabarro BR, Viana HM, Scholz S, et al. (2017) Surface lignin removal on coir fibers by plasma treatment for improved adhesion in thermoplastic starch composites. Carbohydr Polym 165: 429-436.

17.Balakrishnan P, Sreekala, Matjaž Kunaver, Miroslav Huskić, Sabu Thomas (2017) Morphology, transport characteristics and viscoelastic polymer chain confinement in nanocomposites based on thermoplastic potato starch and cellulose nanofibers from pineapple leaf. Carbohydrate Polymers 169: 176-188.

18. Wool R, XS Sun (2011) Bio-based polymers and composites. Academic Press.

19.ASTM D3039/D3039M-08 (2008) Standard test method for tensile properties of polymer matrix composite materials.
20.Averous L (2004) Biodegradable multiphase systems based on plasticized starch: A review. Journal of Macromolecular Science, Part C: Polymer Reviews 44: 231-274.

21.Kozlov P, G Burdygina (1983) The structure and properties of solid gelatin and the principles of their modification. Polymer 24: 651-666.

22. Elsayed $H$ (2012) Influence of flax fibers on properties of starch-based composites. ASME 2012 International Mechanical Engineering Congress and Exposition, American Society of Mechanical Engineers.

23.Shibata S, Y Cao, I Fukumoto (2008) Flexural modulus of the unidirectional and random composites made from biodegradable resin and bamboo and kenaf fibres. Composites Part A: Applied science and Manufacturing 39: 640-646.

24.Firoozmand H, BS Murray, E Dickinson (2007) Fractal-type particle gel formed from gelatin + starch solution. Langmuir 23: 4646-4650.

25.Firoozmand H, BS Murray, E Dickinson (2009) Microstructure and rheology of phase-separated gels of gelatin + oxidized starch. Food Hydrocolloids 23: 1081-1088.

26. Bax B, J Müssig (2008) Impact and tensile properties of PLA/Cordenka and PLA/flax composites. Composites Science and Technology 68: 1601-1607.

27.Bledzki AK, A Jaszkiewicz, D Scherzer (2009) Mechanical properties of PLA composites with manmade cellulose and abaca fibres. Composites Part A: Applied Science and Manufacturing 40: 404-412.

28.Takagi H, Y Ichihara (2004) Effect of fiber length on mechanical properties of "green" composites using a starch-based resin and short bamboo fibers. JSME International Journal Series A Solid Mechanics and Material Engineering 47: 551-555.

29.Shah P, R Prajapati, P Singh (2017) Enrichment of mechanical properties of biodegradable composites containing waste cellulose fiber and thermoplastic starch. European Journal of Advances in Engineering and Technology 4: 282-286.

30.Dos Santos BH (2018) Influence of sugarcane bagasse fiber size on biodegradable composites of thermoplastic starch. Journal of Renewable Materials 6: 176-182. 